http://doi.org/10.15359/ree.13-1.11

\title{
Utopía universitaria
}

\author{
Margarita María Álvarez. \\ Académica de la Universidad Nacional de Santiago del Estero \\ Argentina \\ Marilena Maldonado ${ }^{2}$ \\ Académica de la Universidad Nacional de Santiago del Estero \\ Argentina
}

Recibido 1 de abril de 2009• Aprobado 29 de abril de 2009

Resumen. La universidad en este nuevo milenio está afrontando numerosos cambios, dilemas y retos, y debe prepararse para enfrentarlos conservando un pensamiento utópico. En este contexto, todos los actores de la universidad deberían insistir en el derecho a ensanchar y soñar futuro. Un pensamiento utópico nos permite imaginar una universidad diferente que guíe nuestras actividades como docentes, alumnos, administrativos y autoridades, en aras de lograr la universidad soñada por todos. Esto nos motivó a plantear nuestra utopía universitaria, como un aporte a la reflexión sobre los temas que involucran la universidad.

Palabras clave. Universidad, docentes, alumnos, utopía.

Abstract. Universities are facing numerous changes, dilemmas and challenges in this new millennium, and it must get ready to face them by keeping a utopian thought. In this context all the actors of the university must insist on the right to envision and dream the future.

A utopian thought allows us to imagine a university that is different, one that can guide our activities as teachers, students, administrative personnel and authorities with a view to achieve the university dreamed by all of us.

This has motivated us to state our university utopia as a contribution to the reflection on the topics that involve the university.

Key words. University, teachers, students, utopia.

\footnotetext{
Posee los títulos de: Ingeniera en Computación otorgado por la Universidad Católica de Santiago del Estero, Argentina; Máster en Ingeniería de Software otorgado por la Universidad Politécnica de Madrid, España; Especialista en Docencia Universitaria otorgado por la Universidad Nacional de Cuyo, Mendoza, Argentina. Es docente desde hace varios años en asignaturas de las carreras de Licenciatura en Sistema de Información y Profesorado en Informática de la Universidad Nacional de Santiago del Estero. Ha dirigido y asesorado varios trabajos de graduación. Ha participado de varios proyectos de investigación en la Universidad Nacional de Santiago del Estero y en uno de ellos como coordinadora de un subproyecto. Dispone de comunicaciones y publicaciones. Actualmente, es integrante de la comisión asesora de la Escuela de Informática, y participa en la reestructuración de la Carrera de Licenciatura en Sistema de Información para otorgar títulos intermedios. Correo electrónico: alvarez@unse.edu.ar

2 Posee los títulos de: Ingeniera en Computación otorgado por la Universidad Católica de Santiago del Estero, Argentina; Máster en Ingeniería de Software otorgado por la Universidad Politécnica de Madrid, España; Especialista en Docencia Universitaria otorgado por la Universidad Nacional de Cuyo, Mendoza, Argentina. Es docente desde hace varios años en asignaturas de las carreras de Licenciatura en Sistema de Información y Profesorado en Informática de la Universidad Nacional de Santiago del Estero. Ha participado de varios proyectos de investigación en la Universidad Nacional de Santiago del Estero. Dispone de comunicaciones y publicaciones. Correo electrónico: marilena@unse.edu.ar
} 


\section{INTRODUCCIÓN}

Nos encontramos en una coyuntura histórica en la que las anti-utopías del siglo XX parecieran materializarse en espacios concretos y, por tanto, dejarán de ser utopías para convertirse en la vida real de la sociedad contemporánea. Sin embargo, no podemos darnos el lujo de ponernos tristes. Hoy, más que nunca, necesitamos crear un mundo alterno, un nuevo mundo en el que todos quepan, incluyendo todas las formas de vida en la Tierra. Necesitamos mantener viva la esperanza. No podemos dejarnos afectar por las imágenes apocalípticas que proponen las anti-utopías modernas. Estas visiones inhiben nuestra capacidad para crear utopías, es como si sólo alcanzáramos a vislumbrar lo peor y estuviéramos impedidos para mirar lo hermoso, lo gozoso, lo luminoso de la vida (Gamboa, 2004).

El pensamiento utópico ha formado parte de la universidad a lo largo de buena parte del siglo $\mathrm{XX}$, y no ha desaparecido para nada en la actualidad, a pesar de las prédicas de esa rara mezcla entre el neoliberalismo y el posmodernismo en torno al fin de las utopías (Prieto, 2005). Lo utópico, en tanto que busca lo perfecto, lo mejor posible que aún no llega, está reñido con el achatado y anodino presente (Torres, 2004).

Alfred Whitehead (citado por Tünnermann, 1999) sostiene que "la universidad es imaginación o no es nada" y "que su tarea es la creación del futuro". En tal sentido, la universidad en sí misma genera un tipo de actividad que, también, por sí misma, está lanzada al futuro. En la Universidad se habla de los posibles logros de la investigación, de los futuros profesionales, de quienes en su mano tendrán las decisiones del futuro país (Torres, 2004).

Además, como lo expresa Prieto Castillo (2005), imaginar una institución diferente es parte permanente de la tarea de una universidad, por tanto, de quienes la integran.

Por todo esto, este escrito esboza una mirada utópica de la universidad; pretende ser no sólo un ensayo de opinión, sino un texto de reflexión, y se espera que provoque y facilite la discusión sobre algunos puntos vinculados con la universidad. Es nuestra intención recuperar el ideal universitario como una utopía moderna, que sirva para enfrentar los dilemas y retos que la realidad le plantea a la universidad.

\section{LA MIRADA UTÓPICA}

La misión de la universidad es pensar (la investigación no es otra cosa que pensar al mundo y a nosotros en el mundo), enseñar a pensar (y ésta es la esencia de la educación universitaria), transmitir y acrecentar el pensamiento (en esto consiste la extensión de la cultura) (de la Isla, 1991).

Sin perder de vista la misión de la universidad, nos imaginamos una institución diferente, con transformaciones en sus funciones tradicionales, con alientos de democratización y de servicio a la sociedad, con alternativas pedagógicas.

Por esto, en esta sección expresamos nuestro pensamiento utópico desde el punto de vista de la formación que pretendemos para nuestros alumnos y desde la institución universitaria.

\section{La mirada utópica de nuestros alumnos}

Mucho se habla hoy en día de las complejas exigencias profesionales y de la necesidad de preparar a los alumnos para enfrentar un mundo lleno de incertidumbre, con acelerados 
cambios tecnológicos y en un país en el que es posible que cambien su práctica laboral varias veces en la vida.

Con base en esto, la Organización de las Naciones Unidas para la Educación, la Ciencia y la Cultura (UNESCO, 1998) expresa:

La educación universitaria debería estructurarse en torno a cuatro aprendizajes fundamentales, que en el transcurso de la vida serán para cada persona, en cierto sentido, los pilares del conocimiento: aprender a conocer, es decir, adquirir los instrumentos de la comprensión; aprender a hacer, para poder influir sobre el propio entorno; aprender a vivir juntos, para participar y cooperar con los demás en todas las actividades humanas; $\mathrm{y}$, por último, aprender a ser, un proceso fundamental que recoge elementos de los tres anteriores. Por supuesto, estas cuatro vías del saber convergen en una sola, ya que hay entre ellas múltiples puntos de contacto, coincidencia e intercambio. (s. p.)

Con esta perspectiva de educación universitaria en mente, es que anhelamos, para nuestros alumnos, los siguientes aspectos referentes a su formación:

- $\quad$ Egreso en el tiempo establecido en los currículos.

- $\quad$ Formación de acuerdo con los perfiles e incumbencias planteados en el plan de estudio.

- Incorporación a proyectos de investigación, considerando la investigación como una actividad transversal del currículum que permita a los alumnos aprender a pensar y aprender a actuar en un mundo lleno de incertidumbre.

- Integración al medio, durante su formación en la universidad, por medio de distintas actividades académicas y de servicios, y transferencia de su producción intelectual en función de las demandas sociales.

- Formación en un contexto interuniversitario e intrauniversitario mediante trabajos en red (con docentes, alumnos, egresados, profesionales de la misma carrera, de distintas carreras, de diversas universidades, etc.).

- Contar con recursos tecnológicos y bibliográficos adecuados para su formación.

- $\quad$ Recepción de una formación sustentada en teorías de aprendizaje, enseñanza y desarrollo.

- Liberación de iniciativas en el orden intelectual y cultural.

- Capacidad, como profesionales, para enfrentar y resolver problemas, diagnosticar situaciones y moverse en ellas, tomar decisiones y prever el futuro.

- $\quad$ Responsabilidad en todas sus actividades y actitudes, comprometidos con su misión como persona y como profesional.

- $\quad$ Seguimiento individual (tutorías).

- $\quad$ Evaluación con líneas alternativas (saber, saber hacer y saber ser).

- Posesión de una educación artística, que les permita ser educados para la sensibilidad, la imaginación, la percepción global, el sentido de la armonía y de la belleza y la comprensión de la diversidad de modos, formas y culturas que definen el hombre universal (Escotet, 1996).

- $\quad$ Formación para aprender a emprender, aprender a cuidar y respetar la naturaleza y a seguir aprendiendo (Escotet, 1996). 


\section{La mirada utópica de nuestra institución}

La universidad está atravesando momentos de crisis al igual que nuestro país, así es que no sólo resulta conveniente, sino obligado, pensar en una nueva utopía universitaria, con el fin de que ésta pueda afrontar, exitosamente, las circunstancias que hoy la amenazan.

Esto nos lleva a imaginar una institución diferente, con transformaciones en sus funciones tradicionales, con alientos de democratización y de servicio a la sociedad; expresada por medio de los siguientes anhelos:

- Que no haya grupos de poder y que sea verdaderamente democrática. Un lugar donde se escuchen todas las inquietudes y sugerencias de sus miembros.

- Que no exista absolutismo ni autoritarismo en ningún nivel (aula, carreras, facultades u otras instancias.

- Que la información sobre las actividades académicas y actividades administrativas sea comunicada oportuna y apropiadamente (en tiempo y forma).

- Que existan canales dinámicos de comunicación para recibir y enviar información sobre el contexto, nuestra sociedad, otras instituciones de nivel superior (nacional y extranjeras), investigación y extensión, etc.

- Que esté organizada por departamentos, y se entienda como una unidad epistemológica que pueda ofrecer cursos, realizar actividades de docencia, investigación y extensión, con el fin de propiciar actividades interdisciplinares y pedagógicas, puestas en común para acordar prácticas de enseñanza, sistemas de evaluación, necesidades curriculares, etc.

- Que se caracterice por la investigación científica y tecnológica que genere, promueva y difunda los descubrimientos o hallazgos, y esté abierta a otras comunidades universitarias, para un amplio intercambio de conocimientos.

- Que ofrezca servicios a la comunidad y a las empresas, tales como asistencia técnica e investigación.

- Que sea una universidad de vanguardia, con la capacidad de advertir tendencias futuras en investigaciones, carreras nuevas y en la flexibilización de los planes de estudio, que le permita renovarse constantemente para evitar que se vuelva repetitiva, rutinaria y desactualizada.

- Que los docentes y no docentes tengan remuneraciones dignas.

- Que cuente con tecnologías de la información y la comunicación que posibiliten, entre otras cosas:

- $\quad$ Acercar la universidad al mundo del conocimiento.

- Ampliar el acceso a la educación mediante cursos, carreras, y otras actividades. a distancia.

- $\quad$ Renovar los métodos pedagógicos mediante la creación de nuevos ambientes de aprendizaje.

- Que todos sus miembros estén dispuestos para el interaprendizaje y para entreayudarnos.

- Que tenga gente honesta, con ética profesional y comprometida con el quehacer diario.

- Que las instalaciones sean cómodas, limpias y agradables.

- Que no exista una burocracia paralizante, y que haya la menor cantidad posible de fricciones.

- Que promueva la formación permanente de los docentes en áreas disciplinares específicas y en pedagogía.

- Que sus alumnos reciban una formación académica de excelencia y con un futuro laboral promisorio.

- Que sea responsable con los jóvenes, el saber y la sociedad. 


\section{A MODO DE CIERRE}

Las universidades son el reflejo de la sociedad. Sociedades empobrecidas económica y culturalmente se reflejan en la universidad, políticas educativas desacertadas se reflejan en la universidad, la corrupción se refleja en la universidad, y, así, cuantos hechos, acciones, políticas, etc. existan van a reflejarse en la sociedad.

Esta mirada utópica de la universidad nos permite soñar con el futuro y anhelar que la sociedad sea un reflejo de una universidad docta, libre y sensible.

Creemos que es muy importante que todos los actores de la universidad reflexionemos e imaginemos una institución distinta, y que vivamos con y para una utopía. Esto nos ayudará, seguramente, a mejorar nuestra labor como docentes, como autoridades, como alumnos, como administrativos, con el fin de perseguir que la universidad crezca y perdure.

Además, creemos conveniente resaltar la siguiente frase que expresa Masefield (citado por Prieto, 2005):

Existen pocas cosas terrenales más bellas que una Universidad. Es un lugar donde aquellos que odian la ignorancia pueden esforzarse por saber, donde aquellos que perciben la verdad pueden esforzarse en que otros la vean; donde los buscadores y estudiosos, asociados en la búsqueda del conocimiento, honrarán al pensamiento en todas sus más delicadas formas, acogerán a los pensadores en peligro o en el exilio, defenderán siempre la dignidad del pensamiento y del aprendizaje, y exigirán valores morales a las cosas. Ellos dan a los jóvenes esa íntima camaradería que los jóvenes anhelan, y esa oportunidad de discusión infinita sobre temas que son infinitos, sin los cuales la juventud parecería una pérdida de tiempo. Existen pocas cosas más perdurables que una Universidad. (p. 164)

\section{REFERENCIAS BIBLIOGRÁFICAS}

de la Isla, C. (1991). La universidad: conciencia crítica. Estudios, Vol. VIII, No 25, 69-76.

Escotet, M. A. (1996). Universidad y devenir. Entre la certeza y la incertidumbre. Buenos Aires, Argentina: Editorial IDEAS.

Gamboa, M. A. (2004). Presentación. La Universidad en el nuevo siglo. Reencuentro, $N^{o}$ 041, s. pp.

Organización de las Naciones Unidas para la Educación, la Ciencia y la Cultura (UNESCO). (1998). La Educación Superior del Siglo XXI, Visión y acción. Extraído de la Conferencia Mundial sobre la Educación Superior, realizada en París, del 5 al 9 de octubre de 1998.

Prieto, D. (2005). La Educación Superior. Mendoza, Argentina: Editorial Centro Universitario.

Torres, C. M. (2004). Lo utópico de la Universidad. Reencuentro, $N^{o}$ 041, s. pp.

Tünnermann, C. (1999). La universidad de cara al siglo XX. México D. F.: Editorial Praxis. 